\title{
Cost estimation model in early stage of design through implant miniplate complexity process index
}

\author{
Hendri D.S. Budiono ${ }^{1}$, and Marthan Lassandy ${ }^{1}$ \\ ${ }^{1}$ Department of Mechanical Engineering, Faculty of Engineering, Universitas Indonesia,Depok 16424, Jawa Barat, Indonesia
}

\begin{abstract}
Manufacturing is an activity of processing raw materials into semi-finished or finished products. In addition to manufacturing process, the industry needs product design, material selection, material distribution to create a product. A product produced from a manufacturing system has an index of product complexity that illustrates that the product is made with a certain degree of complexity. The process done on the production of miniplate implants is the process of forming an outside profile, slicing process, the hole process, micro finishing, and ultrasonic cleaning. Quantitative methods used are feature-based cost, operationbased cost, and breakdown approach. Feature based cost consists of cost by feature, that is the cost outside profile, slicing process, the hole process, micro finishing, and ultrasonic cleaning costs. Operation based cost consists of set up, operation, and unloading costs. Breakdown approach consists of cost set tool, set workpiece, and programming on set up, operator cost, material, overhead, energy, and tool, unloading cost consists of release tool cost and release workpiece. Process complexity of the miniplate implant manufacturing process in the early stage of the design can be done with the help of Siemens Nx 8 software as a timing guide with the same parameters and has been tested for the correlation. The process complexity index of the miniplate implant manufacturing process is 100.08 and the estimated process cost of the miniplate implant manufacturing process using a combined analytical technique is IDR 139.150,94.
\end{abstract}

\section{Introduction}

Manufacturing is an activity of processing raw materials into semi-finished or finished products. In addition to manufacturing process, the industry needs product design, material selection, material distribution processes to create a product. A product produced from a manufacturing system has an index of product complexity that illustrates that the product is made with a certain degree of complexity. Design and manufacturing activities are generally integrated, from the drawing process, the delivery of images to the production department, the selection of manufacturing processes and materials used, and the latter continuing in the production process. It can be seen from Figure 1 that the design of the product itself has a big role because the decisions made in the design process before the detailed design can affect $70-80 \%$ of the cost of developing and manufacturing the product [1].

The methodology was established to produce a measure of product complexity that could be extended to cover multiple sides of process complexity, as shown in Figure 2 [2].

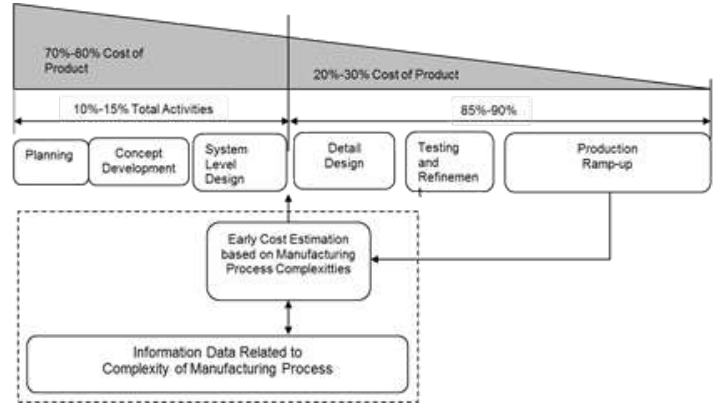

Fig. 1. Design Concept [1]

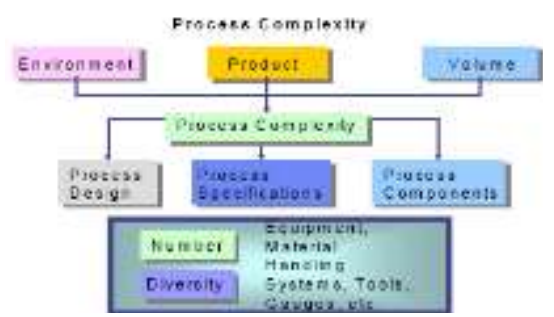

Fig. 2.Process Complexity[2]

Process complexity is a function of product design, volume requirements, and work environment. The

*Corresponding author: hendri@eng.ui.ac.id, marthan.lassandy@ui.ac.id 
complexity of a process is a combination of several elements such as environment, product, and capacity. Based on the complexity, the process can include process design, process specifications, and some components of a process.

Cost estimating has a direct relationship with the performance and effectiveness of business firms because over estimation can result in business losses in the market, and also under estimation can cause financial losses to the company. As a result, an important research effort has evolved in the exploring design implications, new techniques, and methods to produce accurate and consistent cost estimates not only to produce optimum design solutions but also to obtain maximum cost satisfaction at low cost, good quality, and time delivery [3].

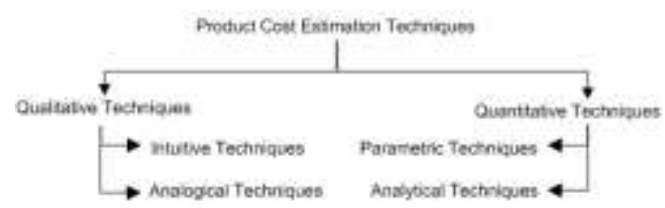

Fig.3.Product Cost Estimation Techniques [4]

Cost estimating is critical for the manufacturing industry. Estimated manufacturing costs in the early design phase are important for industrial engineers. The cost information of a product should be immediately provided to the product designer. Since the process plan is set and production is in progress, the cost changes to the design and process plan will outweigh the cost of production for the current design [5]. The aim of the research is to estimate the cost in early stage of design through the complexity process index.

\section{Methods}

\subsection{Main Design}

Initial designs were designed to perform the miniplate implant manufacturing process. According to the design, it is expected to be the same specifications as the properties and processes of titanium material.[5] Figure 6 shows the implant miniplate product that has been produced.[6].

Figure 4 shows a miniplate implant and the dimension that must be known to proceed to the analysis phase of process complexity and cost. There are 5 stages process to generate a miniplate implant as presented in figure 5 .

\subsection{Steps}

The implementation is calculating machining cost calculations with machining time obtained from equation model into machine process cost to process complexity through standard used.
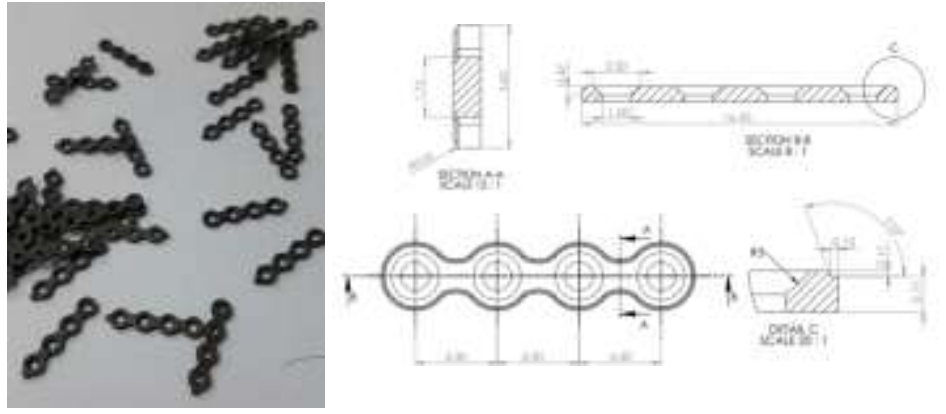

Fig 4.(a). Implant Miniplate, (b). Biomedical Implant Miniplate Dimension

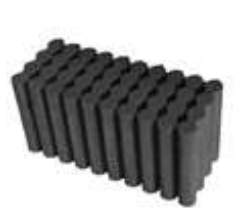

(a)

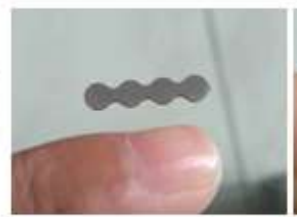

(b)

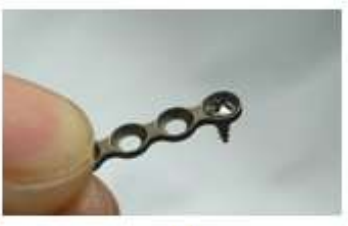

(c)

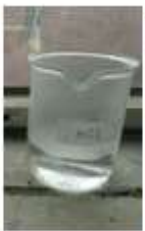

(d)

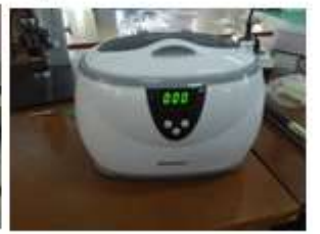

(e)
Fig 5.(a) Outside Profile Forming, (b) Slicing Process, (c) Hole Process (d) Microfinishing, (e)Ultrasonic Cleaning

1. Regarding the complexity of the machining process: [7]

a. Feature dimension must be ensured to be within the group and dimension under study. [8]

b. Physical parameters are calculated based on the components used to perform a process stage.

c. Perform shape weighting, geometry, and tolerance in a process stage.

d. Determine the process complexity of a process, which are set up, operational, and unloading at each stage.

2. Time is used to determine the production time of one unit of product type data in one process cycle. Time for each section is used to calculate the cost of production from one process unit to one product unit.

3. Related to cost calculation: [9]

a. Local standard fees are used in calculations, such as operator/hour costs, costs due to the cost of electricity use on machines, machine power, machine prices used in accordance with existing data in the industry.

b. Cost data and tool life and raw material prices of standard materials used.

c. Grouping the steps of the miniplate implants process based on the quantitative method used. The methodsused are Operational Based Approach, Breakdown Approach, and Featured Based Approach.

4. Implementation of early design model is only on profile process using wirecut EDM. This 
implementation phase uses the Siemens $\mathrm{Nx} 8$ to determine the time on various dimensions and SPSS to show the correlation. Siemens Nx 8 is one of CAM software that can simulate wirecut $\mathrm{CNC}$ machining and the default parameters on actual machine are availaible on. SPSS is an application to perform statistical analysis. There are 2 variables, actual data and software data which must be correlated.

\subsection{Results}

The calculation of the total machinery implants of miniplate implants is calculated by summing up all direct costs and indirect costs. This calculation is obtained by converting machining time into direct labor cost calculation, energy cost, and overhead cost using predefined standard. Table 1 shows all of the results of process time, complexity, cost.

Table1.Time-Complexity-Cost

\begin{tabular}{|c|c|c|c|c|c|}
\hline \multirow{2}{*}{ No. } & \multicolumn{2}{|c|}{ Process } & $\begin{array}{c}\text { Time } \\
\text { (second) }\end{array}$ & Complexity & $\begin{array}{c}\text { Cost } \\
\text { (IDR) }\end{array}$ \\
\hline \multirow{3}{*}{1.} & \multirow{2}{*}{$\begin{array}{c}\text { Outside Profile } \\
\text { Forming }\end{array}$} & Set Up & 903,5 & 12,9 & 7304,17 \\
\cline { 3 - 6 } & & Operational & 246 & 3,5 & 8290,85 \\
\cline { 3 - 6 } & Unloading & 442 & 5,03 & 3683,3 \\
\hline \multirow{3}{*}{2.} & Set Up & 706,3 & 6,4 & 3385,83 \\
\cline { 3 - 6 } & \multirow{2}{*}{ Slicing Process } & Operational & 113 & 3,52 & 5613,97 \\
\cline { 3 - 6 } & & Unloading & 234,4 & 8,84 & 1953,33 \\
\hline \multirow{3}{*}{3.} & \multirow{2}{*}{ Hole Process } & Set Up & 882 & 13,32 & 7350 \\
\cline { 3 - 6 } & & Operational & 254 & 3,5 & 23762,99 \\
\cline { 3 - 6 } & & Unloading & 264 & 8,41 & 2200 \\
\hline \multirow{3}{*}{4.} & Set Up & 81 & 6,51 & 675 \\
\cline { 3 - 6 } & \multirow{3}{*}{ Microfinishing, } & Operational & 3600 & 2,42 & 63333,56 \\
\cline { 3 - 6 } & & Unloading & 113 & 7,08 & 941,67 \\
\hline \multirow{3}{*}{5.} & \multirow{2}{*}{ UltrasonicCleaning } & Set Up & 46 & 8,9 & 383,33 \\
\cline { 3 - 6 } & & Operational & 180 & 2,86 & 8172,88 \\
\cline { 3 - 6 } & Unloading & 252 & 6,89 & 2100 \\
\hline
\end{tabular}

Table2.Quantitative Method Comparison

\begin{tabular}{|c|c|c|c|c|c|c|c|c|c|c|c|}
\hline \multicolumn{2}{|c|}{ Featured Based } & \multicolumn{2}{|c|}{$\begin{array}{c}\text { Operation Based } \\
\text { Approach }\end{array}$} & \multicolumn{2}{|c|}{ Breakdown Approach } & \multicolumn{2}{|c|}{ Featured Based } & \multicolumn{2}{|c|}{$\begin{array}{c}\text { Operation Based } \\
\text { Approach }\end{array}$} & \multicolumn{2}{|c|}{ Breakdown Approach } \\
\hline Process & $\begin{array}{l}\text { Cost } \\
\text { (IDR) }\end{array}$ & Process & $\begin{array}{l}\text { Cost } \\
\text { (IDR) }\end{array}$ & Item & $\begin{array}{l}\text { Cost } \\
\text { (IDR) }\end{array}$ & Process & $\begin{array}{l}\text { Cost } \\
\text { (IDR) }\end{array}$ & Process & $\begin{array}{c}\text { Cost } \\
\text { (IDR) }\end{array}$ & Item & $\begin{array}{l}\text { Cost } \\
\text { (IDR) }\end{array}$ \\
\hline \multirow{9}{*}{$\begin{array}{l}\text { Outside } \\
\text { profile } \\
\text { forming }\end{array}$} & \multirow{9}{*}{$\begin{array}{c}19278,3 \\
6\end{array}$} & \multirow{3}{*}{ Set Up } & \multirow{3}{*}{7304,17} & Set Tool & 1666,67 & \multirow{9}{*}{$\begin{array}{l}\text { Micro } \\
\text { finishing }\end{array}$} & \multirow{9}{*}{64950,23} & \multirow[b]{2}{*}{ Set Up } & \multirow{2}{*}{675} & Set Tool & 191,7 \\
\hline & & & & $\begin{array}{c}\text { Set } \\
\text { Workpiece }\end{array}$ & 4766,67 & & & & & $\begin{array}{c}\text { Set } \\
\text { Workpiece }\end{array}$ & 483,3 \\
\hline & & & & $\begin{array}{c}\text { Programmin } \\
\mathrm{g}\end{array}$ & 870,83 & & & & 63333,5 & Operator & 30000 \\
\hline & & \multirow{5}{*}{$\begin{array}{c}\text { Operationa } \\
1\end{array}$} & \multirow{5}{*}{8290,85} & Operator & 2050 & & & Operational & 6 & Overhead & 0,23 \\
\hline & & & & Material & 1277,84 & & & & & Tool & $\begin{array}{c}33333,3 \\
3\end{array}$ \\
\hline & & & & Overhead & 1355,01 & & & \multirow{4}{*}{ Unloading } & \multirow{4}{*}{941,67} & Release Tool & 733,33 \\
\hline & & & & Energy & 943 & & & & & & \\
\hline & & & & Tool & 2665 & & & & & Release & 20834 \\
\hline & & Unloading & 3683,3 & $\begin{array}{c}\text { Release } \\
\text { Workpiece }\end{array}$ & 3683,33 & & & & & Workpiece & 208,34 \\
\hline \multirow{9}{*}{$\begin{array}{l}\text { Slicing } \\
\text { process }\end{array}$} & \multirow{9}{*}{$\begin{array}{c}10953,1 \\
3\end{array}$} & \multirow{2}{*}{ Set Up } & \multirow[t]{2}{*}{3385,83} & $\begin{array}{c}\text { Set } \\
\text { Workpiece }\end{array}$ & 2765 & \multirow{9}{*}{$\begin{array}{c}\text { Ultra } \\
\text { sonic } \\
\text { Cleaning }\end{array}$} & \multirow{9}{*}{$10.656,2$} & \multirow{3}{*}{ Set Up } & \multirow{3}{*}{383,33} & Set Tool & 150 \\
\hline & & & & $\begin{array}{c}\text { Programmin } \\
\mathrm{g}\end{array}$ & 620,83 & & & & & $\begin{array}{c}\text { Set } \\
\text { Workpiece } \\
\end{array}$ & 175 \\
\hline & & \multirow{4}{*}{$\begin{array}{c}\text { Operationa } \\
1\end{array}$} & \multirow{4}{*}{5613,97} & Operator & 850 & & & & & Programming & 58,33 \\
\hline & & & & Overhead & 3267,97 & & & \multirow{4}{*}{ Operational } & & Operator & 1500 \\
\hline & & & & Energy & 391 & & & & 8172,88 & Overhead & 2,76 \\
\hline & & & & Tool & 1105 & & & & & Energy & 3,45 \\
\hline & & & & Release Tool & 1023,33 & & & & & Tool & 6666,67 \\
\hline & & Unloading & 1953,33 & & & & & & & Release Tool & 900 \\
\hline & & Uniodaling & 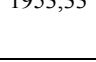 & Workpiece & 930 & & & Unloading & 2100 & $\begin{array}{c}\text { Release } \\
\text { Workpiece }\end{array}$ & 1200 \\
\hline & & & & Set Tool & 1941,7 & & & Total Cost & $39.150,94$ & & \\
\hline & & Set Up & 7350 & $\begin{array}{c}\text { Set } \\
\text { Workpiece }\end{array}$ & 4200 & & & & & & \\
\hline & & & & $\begin{array}{c}\text { Programmin } \\
\mathrm{g}\end{array}$ & 1183,3 & & & & & & \\
\hline & & & & Operator & 1808,33 & & & & & & \\
\hline $\begin{array}{l}\text { Hole } \\
\text { process }\end{array}$ & 33312,9 & & 23762,9 & Overhead & 1536,09 & & & & & & \\
\hline & & $\begin{array}{c}\text { Operationa } \\
1\end{array}$ & 9 & Energy & 831,83 & & & & & & \\
\hline & & & & Tool & $\begin{array}{c}19586,7 \\
2 \\
\end{array}$ & & & & & & \\
\hline & & & & Release Tool & 1008,3 & & & & & & \\
\hline & & Unloading & 2200 & $\begin{array}{c}\text { Release } \\
\text { Workpiece } \\
\end{array}$ & 1191,7 & & & & & & \\
\hline
\end{tabular}

There are five processes as previously mentioned to the production of miniplate implants. In each process has three important stages of set up, operational, and unloading. Time is the length of the process that is lived in one stage. Complexity is to explain the complexity index of related processes. Cost is the cost required to work on one such process. Set up on the slicing process tends to be smaller because there is no setting tool, because the tool used is still the same as the previous process that is outside profile forming. Operations in the three processes of outside profile forming, hole process, and microfinishing have a high cost because the raw material price and tool variables are placed in the process. The tool used is self-produced electrodes.

Table 1 explains the results of time, complexity, and cost of the stages those shown on figure 5.The processes are in the position of operation based cost method which has element set up, operation, and unloading. Table 2 explains how to use the selected quantitative method of feature based cost, operation based cost, and breakdown 
approach cost on the production of miniplate implants. Users can choose which costs are needed quickly and accurately to the required process. The total cost required is IDR $139.150,94$. Users who want to use one or two processes just add up the two processes.

Table 3. Actual Data vs. Siemens Nx Data on Outside profile forming

\begin{tabular}{|c|c|c|c|c|}
\hline No & Perimeter & Feed Rate & Actual Data & Software Data \\
\hline 1 & 37,78 & \multirow{8}{*}{$13 \mathrm{~mm} / \mathrm{min}$} & 235 & 209 \\
\hline 2 & 39,03 & & 240 & 214 \\
\hline 3 & 40,28 & & 246 & 219 \\
\hline 4 & 41,53 & & 252 & 224 \\
\hline 5 & 42,79 & & 257 & 229 \\
\hline 6 & 44,04 & & 263 & 234 \\
\hline 7 & 45,28 & & 268 & 239 \\
\hline 8 & 46,52 & & 274 & 244 \\
\hline
\end{tabular}

\begin{tabular}{|c|c|c|c|c|}
\hline \multicolumn{3}{|c|}{ Control Variables } & \multirow{2}{*}{$\begin{array}{l}\text { Actual } \\
1.000\end{array}$} & \multirow{2}{*}{$\begin{array}{l}\text { Software } \\
0.098\end{array}$} \\
\hline Perimeter & Actual & Correlation & & \\
\hline & & Significant (2-tailed) & & 0.835 \\
\hline & & df & 0 & 5 \\
\hline & Software & Correlation & 0.098 & 1.000 \\
\hline & & Significant (2-tailed) & 0.835 & \\
\hline & & df & 5 & 0 \\
\hline
\end{tabular}

Fig 6. Correlation Result Using Software SPSS

Figure 6 explains the results of the implementation in the case study compared to other products calculated using Siemens Nx 8 which resulted in a linear time. The machining time is strongly influenced by the perimeter or the distance of the cutting tool path. [10] The calculation model of process complexity can result in the value of complexity due to dimensional changes through the perimeter or the distance of the cutting tool path.

\section{Conclusion}

The process done in the production of miniplate implants is the process of forming an outside profile, slicing process, the hole process, micro finishing, and ultrasonic cleaning. The process complexity index of the miniplate implant manufacturing process is 100.08 and the estimated process cost of the miniplate implant manufacturing process using a combined analytical technique is IDR $139.150,94$.

Quantitative methods used are feature-based cost, operation-based cost, and breakdown approach. Feature based cost consists of cost by feature that is the costs of set tool, set workpiece, and programming on set up, operator, material, overhead, energy, and tool. Unloading cost consists of release tool cost and release workpiece cost. The process and process complexity of the miniplate implant manufacturing process in the early stages of the design can be done with the help of Siemens $\mathrm{Nx} 8$ software as a timing guide with the same parameters has been tested for the correlation.

\section{References}

1. Budiono, H.D., G. Kiswanto, And T.P. Soemardi, Method And Model Development For Manufacturing Cost Estimation During The Early Design Phase Related To The Complexity Of The Machining Processes. International Journal Of Technology, 2014. 5(2): P. 183-192.

2. El Maraghy, W. And R. Urbanic, Assessment Of Manufacturing Operational Complexity. Cirp AnnalsManufacturing Technology, 2004. 53(1): P. 401-406.

3. Shehab, E. And H. Abdalla, Manufacturing Cost Modelling For Concurrent Product Development. Robotics And Computer-Integrated Manufacturing, 2001. 17(4): P. 341-353.

4. Niazi, A., Et Al., Product Cost Estimation: Technique Classification And Methodology Review. Journal Of Manufacturing Science And Engineering, 2006. 128(2): P. 563-575.

5. Geetha, M., Et Al., Ti Based Biomaterials, The Ultimate Choice For Orthopaedic Implants-A Review. Progress In Materials Science, 2009. 54(3): P. 397-425.

6. Qosim, N., Et Al., Development Of Ti-6al-4v BasedMiniplate Manufactured By Electrical Discharge Machining As Maxillofacial Implant. Journal Of Fundamental And Applied Sciences, 2018. 10(3s): P. 765-775.

7. Lassandy, M., Et Al., Calculation Of The CNC EDM Complexity Process For Biomedical Implants. Journal Of Fundamental And Applied Sciences, 2018. 10(5s): P. 819-830.

8. Jung, J.-Y., Manufacturing Cost Estimation For Machined Parts Based On Manufacturing Features. Journal Of Intelligent Manufacturing, 2002. 13(4): P. 227-238.

9. Ou-Yang, C. And T. Lin, Developing An Integrated Framework For Feature-Based Early Manufacturing Cost Estimation. The International Journal of Advanced Manufacturing Technology, 1997. 13(9): P. 618-629.

10. Prosiding Snatika (Seminar Nasional Teknologi, Informasi, Komunikasi dan Aplikasinya) Vol 4 (2017). 